\title{
Save the Date!
}
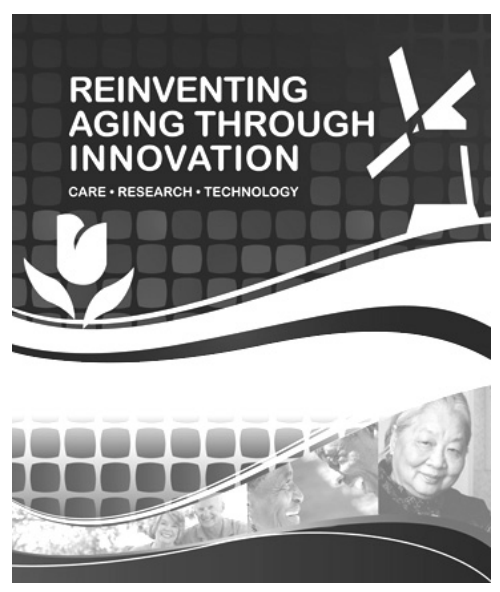

\section{$15^{\text {th }}$ International Congress}

Reinventing Aging Through Innovation

Care $\bullet$ Research $\bullet$ Technology

\author{
6-9 September 2011 \\ The Hague, The Netherlands
}

The International Psychogeriatric Association (IPA) is committed to bringing the newest information from the field to its scientific programs.

For information contact the IPA Secretariat:

Email: ipa@ipa-online.org Web: www.ipa-online.org

IPA ... Better Mental Health for Older People 


\section{International FI PA $=$ Psychogeriatric Association}

\section{IPA Junior Research Awards}

\section{Submissions are due 15 April 2011}

Presented every two years at the IPA Congress, the Junior Research Awards in Psychogeriatrics were established in 1989 to recognize the best original, previously unpublished research in the field of Psychogeriatrics by junior researchers and encourage them to continue their groundbreaking work and participate in the field and IPA. Past award recipients include many scientists who have demonstrated outstanding leadership in the field.

The recipients will present their award-winning research:

- Session at the IPA 2011 Congress, 6-9 September 2011 in The Hague, The Netherlands

- Papers will be published in International Psychogeriatrics, IPA's Journal

In addition, each award recipient will receive:

- Complimentary 2011 IPA Congress registration

- US \$1,500 toward travel and accommodations for the Congress

- Complimentary one-year membership in IPA

For more information, visit IPA's website, http://www.ipa-online.org.

\section{Submissions are due 15 April 2011 \\ Please send submissions electronically to: \\ researchawards@ipa-online.org}

IPA Junior Research Awards in Psychogeriatrics Committee

International Psychogeriatric Association

550 Frontage Road, Suite 3759

Northfield, IL 60093

United States

Tel: +1.847.501.3310; Fax: +1.847.501.3317

Email: researchawards@ipa-online.org 


\section{Coming soon as a webinar!}

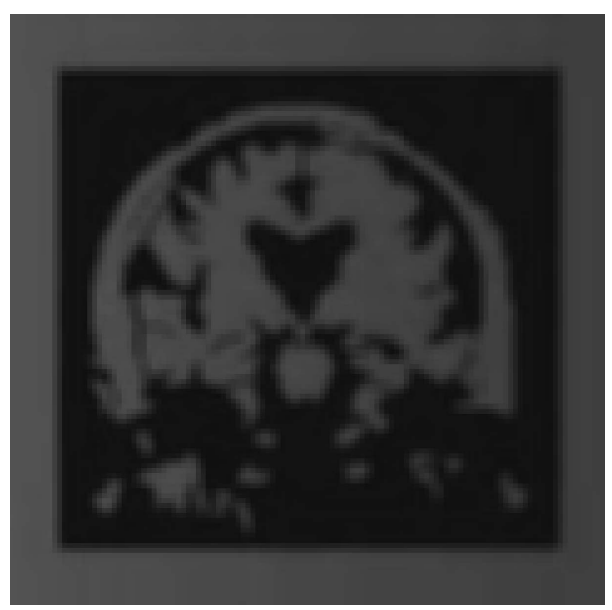

\section{IPA Neuroimaging in Dementia}

\section{Attend this popular IPA workshop and never leave your office!}

Starting soon, IPA is planning to offer this program online. Presented by the same outstanding international experts, providing information on the latest advances in neuroimaging with real life examples and using an interactive teaching style, the webinars are destined to be as successful as the original workshop which has been offered many times and always receiving excellent evaluations!

For more information, watch the IPA Bulletin and IPA Website.

Email: ipa@ipa-online.org Web: www.ipa-online.org IPA ... Better Mental Health for Older People

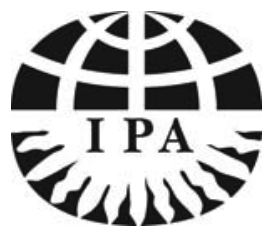




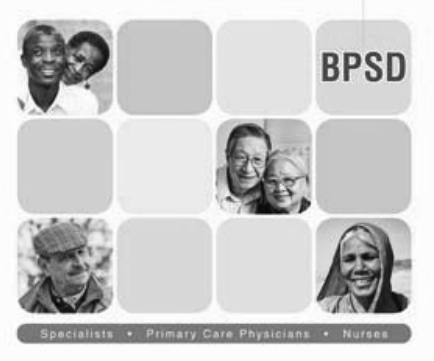

\section{Newly Revised!}

\section{The IPA Complete Guide to Behavioral and Psychological Symptoms of Dementia (BPSD)}

BPSD are recognizable, understandable and treatable. Appropriate management strategies of BPSD are important factors in improving our care of dementia patients and their caregivers.

Developed in 1998, updated in 2002 and recently revised, the International Psychogeriatric Association (IPA) offers this popular comprehensive resource with modules that provide a useful overview of the presentation and causes of BPSD, giving constructive guidance on treatment interventions, both pharmacological and non-pharmacological, coupled with information on caregiver education and support.

Modules:

1 - An introduction to BPSD

2 - Clinical issues

3 - Etiology

4 - Role of family caregivers
5 - Non-pharmacological treatments

6 - Pharmacological treatments

7 - Cross-cultural and transnational considerations

... PLUS guides specifically designed for nurses and primary care physicians are also available!

Available online at no charge to IPA members!

Join IPA today!

www.ipa-online.org 


\section{Encourage a Colleague to Join}

The International Psychogeriatric Association (IPA) is the leading multidisciplinary, international organization dedicated to the advancement of geriatric mental health knowledge.

\section{Benefits of IPA Membership Include}

- An opportunity to interact with colleagues around the world who share an interest in advancing research, education, and theory about mental health in older people

- Education and meetings reflecting the many disciplines in Psychogeriatrics and the collective expertise of the world; IPA members receive special "members only" rates for all our meetings and activities

- A subscription to International Psychogeriatrics, IPA's peer-reviewed journal, which includes eight issues per year and any additional special-focus supplements

- The IPA Bulletin, an informative quarterly newsletter

- IPA Online - the IPA website - including member area with special features including access to fellow members, and the IPA Learning Portal

- Support the growth of Psychogeriatrics around the world, including contributing to the Sponsored Member Program to help associations in developing countries pass knowledge to their members

- Behavioral and Psychological Symptoms of Dementia (BPSD) Education Materials are available to IPA members in electronic format at no charge. The BPSD materials include the newly revised seven module IPA Complete Guide to $B P S D$, the Primary Care Physician's Guide to BPSD, and the Nurses' Guide to $B P S D$.

IPA's membership dues have been adjusted to accommodate the needs of a wide variety of colleagues worldwide. To find out what the membership rates are for your country, please visit www.ipa-online.org.

To join or to obtain a membership application, bookmark the IPA website at http://www.ipa-online.org, or contact:

International Psychogeriatric Association

E-mail: membership@ipa-online.org Website: http://www.ipa-online.org

Telephone: +1.847 .501 .3310 • Fax: +1.847.501.3317

550 Frontage Road, Suite 3759

Northfield, IL 60093 USA

\section{IPA ... Better Mental Health for Older People}




\section{CAMBridge}

\section{Medicine}

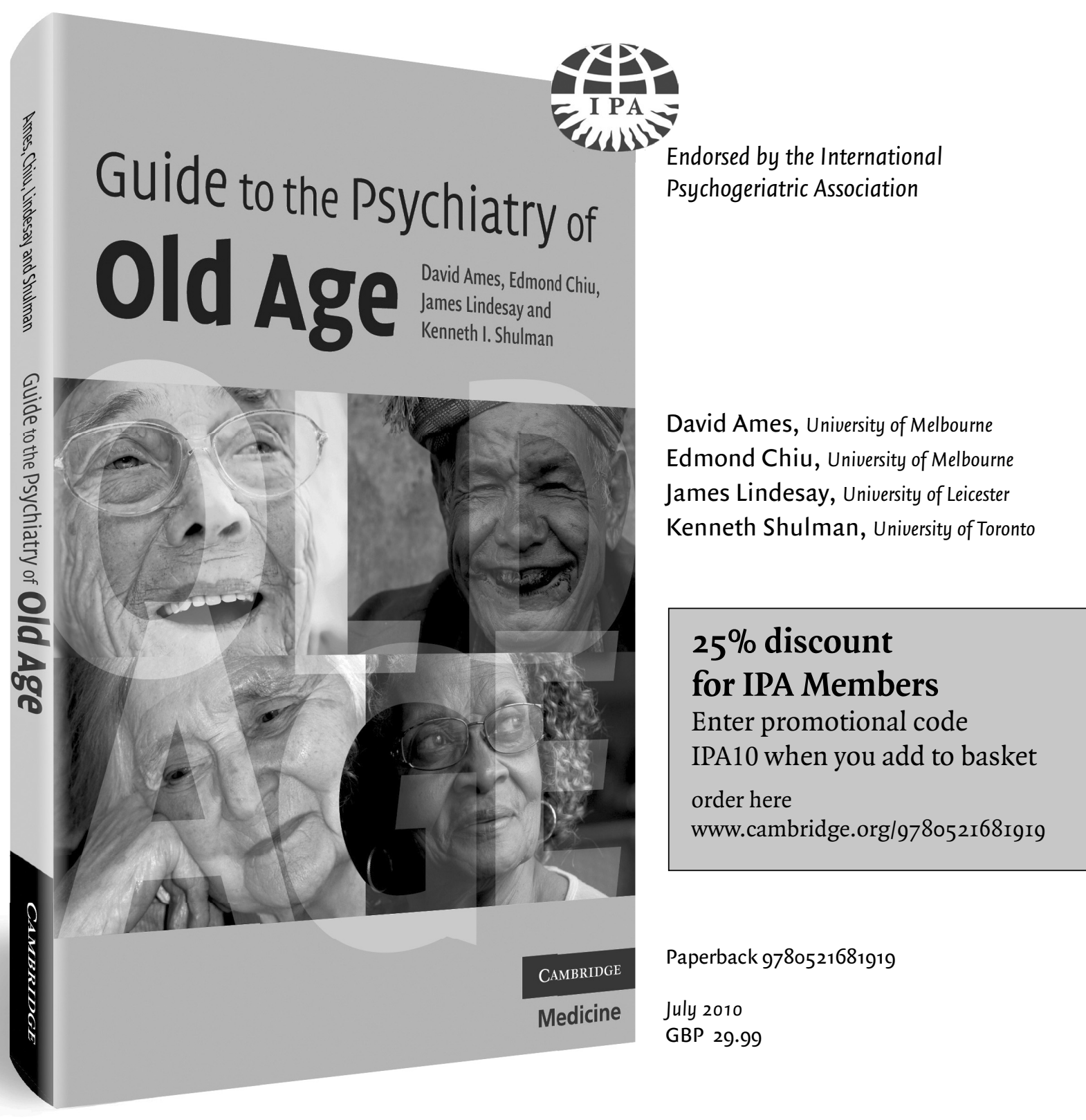

\section{Compact, accessible and affordable}

Each chapter is sharp, clear and practical, enhanced by tables and diagrams for quick assimilation and reference on the ward or in the clinic Coverage also includes legal and ethical issues, and the neglected topic of alcohol and drug abuse in the elderly 


\section{圈图 UNIVERSITY OF

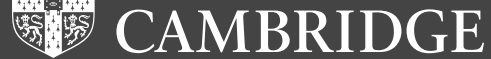

\section{Institute of Continuing Education}

\section{Cambridge Neuropsychopharmacology Programme}

23-25 June 2011, Madingley Hall, Cambridge
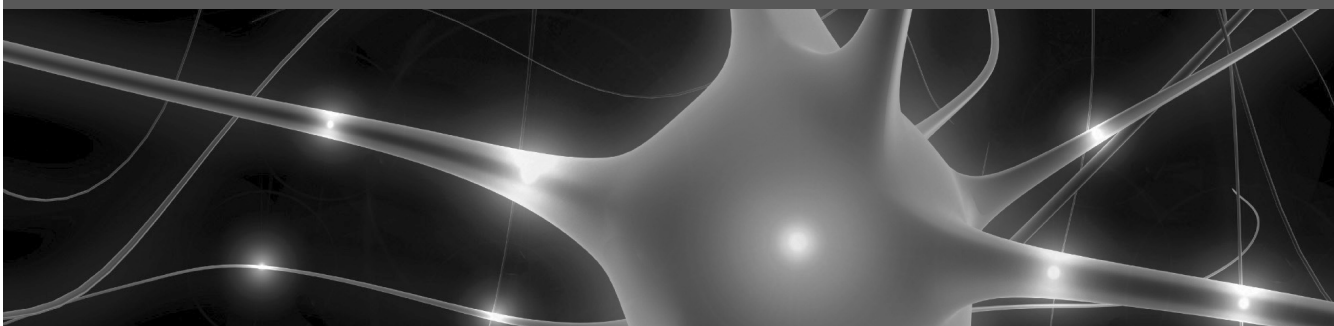

In June 2011, the University of Cambridge Institute of Continuing Education (ICE) will host an extraordinary event. For three days, some of the world's finest psychiatrists, both practitioners and academics, will give their time to speak on the most recent advances in the field of neuropsychopharmacology.

Held at historic Madingley Hall, this residential programme is led by world-renowned clinician and author Dr Stephen Stahl (Essential Psychopharmacology) and Professor Peter B Jones, Head of Psychiatry at the University of Cambridge School of Clinical Medicine.

Delegates will be invited to attend morning seminars, join discussion groups each afternoon and participate fully with speakers and colleagues.

The three-day residential course costs $£ 1,850$, to include room and board at Madingley Hall; book before 1 January 2011 for a $£ 200$ discount on the full price. Online booking is available at www.ice.cam.ac.uk/cnp.

\section{Speakers include Dr Stephen M Stahl, Professor Peter Jones, Professor Barbara J} Sahakian, Professor Trevor Robbins, Professor Ed Bullmore and Professor Phillip Cowen.

Topics covered at the course will include the major disease states and their neurobiology across the spectrum of mental illness and the mechanisms of action of the psychopharmacologic agents used to treat these conditions. Throughout the course, the application of these concepts and clinical skills will be illustrated with reference to a wide range of descriptive case studies. Full details can be found on www.ice.cam.ac.uk/cnp.

\section{www.ice.cam.ac.uk/cnp}

NEUROSCIENCE

EDUCATION

I. INSTITUTE
YNIVERSTYY OF

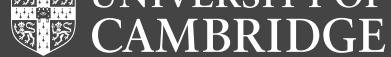

Department of Psychiatry
CAMBRIDGE

UNIVERSITY PRESS 


\section{International}

\section{Scope and contributions}

International Psychogeriatrics is written by and for those doing clinical, teaching, and research work with older people. It is the official journal of the International Psychogeriatric Association (IPA) and is published by Cambridge University Press, Cambridge, UK. Although it is primarily concerned with psychogeriatrics, the journal welcomes contributions from all concerned with the field of mental health and aging. Original research papers are particularly sought.

Contributions include original research articles, case reports, reviews of the literature, book reviews, letters to the editor, and editorials. Apart from editorials and book reviews, which are commissioned, contributions to International Psychogeriatrics are spontaneously written and submitted by authors. Papers are reviewed by two expert reviewers selected by the Editor-in-Chief. At present, about half of the papers submitted are accepted for publication. The journal's Science Citation Index impact factor is 2.506 (2009). Submission of a paper implies that it is neither under consideration for publication elsewhere, nor previously published in English. Manuscripts must be formatted double-spaced with ample margins on all sides and the pages should be numbered. International Psychogeriatrics uses the spelling of American English. Manuscripts written by those whose primary language is not English should be edited carefully for language prior to submission. The journal has a Language Assistance Panel consisting of both native English speakers willing to check mauscripts for style prior to submission, and bilingual experts willing to assist with the translation of manuscripts into English. Further details including contact information for individual panel members can be found at both the journal and IPA websites (journals.cambridge.org/ipg and www.ipa-online.org).

An up to date version of the journal's instructions for contributors can be found at the International Psychogeriatrics website journals. cambridge.org/ipg. Please read these instructions carefully before submitting articles. Articles that are not prepared in accordance with these guidelines will be returned to authors.

Manuscripts should be submitted online via our manuscript submission and tracking site, <http://mc.manuscriptcentral.com/ipg>. Full instructions for electronic submission are available directly from this site.

\section{Important Addresses}

Office of the Editor-in-Chief

NicolaT. Lautenschlager Editor-in-Chief, International

Psychogeriatrics

Normanby House,

St George's Hospital,

283 Cotham Rd.,

Kew,Victoria 3101,

Australia

Email:ipaj-ed@unimelb.edu.au

Tel +61398160485

Fax +61398160477

Enquiries about advertising should be sent to the Journal's Promotion Department of the Cambridge or American Branch of Cambridge University Press.

\section{For business matters:}

Ms. Susan M. Oster

Managing Editor, International Psychogeriatrics

International Psychogeriatric Association

550 Frontage Road,

Suite 3759

Northfield, IL 60093

USA

Email:ipa@ipa-online.org

Tel: +18475013310

Fax: +1 8475013317

Web: www.ipa-online.org

\section{For book review matters:}

Dr. Michael Philpot

Maudsley Hospital,

Mental Health of Older Adults Directorate

115 Denmark Hill,

London SE5 8AZ

U.K.

Email:

mike.philpot@slam.nhs.uk

Tel: +44 (0)203228 1640

Fax: +44(0)203228 1619 .

This journal issue has been printed on FSC-certified paper and cover board. FSC is an independent, non-governmental, not-for-profit organization established to promote the responsible management of the world's forests. Please see www.fsc.org for information. 


\section{International Psychogeriatrics}

CONTENTS

Editorial 171 Die Zeit, die ist ein sonderbar Ding [Time is a strange thing] David Ames (Australia)

Reviews 174 Psychogeriatric inpatient unit design: a literature review John T. Dobrohotoff and Robert H. Llewellyn-Jones (Australia)

190 Sleep in dementia and caregiving - assessment and treatment implications: a review David R. Lee and Alan J. Thomas (U.K.)

Original Research 202 Leg length, skull circumference, and the prevalence of dementia in low and middle income countries: a 10/66 Articles population-based cross sectional survey Martin Prince (U.K.), Daisy Acosta (Dominican Republic), Alan D Dangour, Ricardo Uauy (U.K.), Mariella Guerra (Perú), Yueqin Huang (China), K. S. Jacob (India), Juan J. Llibre Rodriguez (Cuba), Aquiles Salas (Caracas), Ana Luisa Sosa (Mexico), Joseph D. Williams (India), Isaac Acosta (Mexico), Emiliano Albanese, Michael E. Dewey, Cleusa P. Ferri, Robert Stewart (U.K.), Ciro Gaona (Venezuela), A. T. Jotheeswaran, P. Senthil Kumar (India), Shuran Li (China), Juan C. Llibre Guerra (Cuba), Diana Rodriguez (Perú) and Guillermina Rodriguez (Dominican Republic)

214 Persistence of neuropsychiatric symptoms over six months in mild cognitive impairment in community-dwelling Korean elderly Seung-Ho Ryu, Jee Hyun Ha, Doo-Heum Park, Jaehak Yu (Korea) and Gill Livingston (U.K.)

221 Development and evaluation of an educational intervention for general practitioners and staff caring for people with dementia living in residential facilities

Christopher Beer, Rachel Lowry, Barbara Horner, Osvaldo P. Almeida, Samuel Scherer, Nicola T. Lautenschlager, Nick Bretland, Penelope Flett, Frank Schaper and Leon Flicker (Australia)

230 Cognitive decline in the behavioral variant of frontotemporal dementia Janine Diehl-Schmid, Susanne Bornschein, Corina Pohl, Hans Förstl, Alexander Kurz and Thomas Jahn (Germany)

238 Prescribing trends in cognition enhancing drugs in Australia Samantha A. Hollingworth and Gerard J. Byrne (Australia)

246 Evaluation of Alzheimer's Australia Vic Memory Lane Cafés Briony Dow, Betty Haralambous, Courtney Hempton, Susan Hunt and Diane Calleja (Australia)

256 Memory and communication support in dementia: research-based strategies for caregivers Erin R. Smith, Megan Broughton, Rosemary Baker, Nancy A. Pachana, Anthony J. Angwin, Michael S. Humphreys, Leander Mitchell, Gerard J. Byrne, David A. Copland, Cindy Gallois (Australia), Desley Hegney (Singapore/Australia) and Helen J. Chenery (Australia)

264 A longitudinal study examining the independence of apathy and depression after stroke: the Sydney Stroke Study Adrienne Withall, Henry Brodaty, Annette Altendorf and Perminder S. Sachdev (Australia)

274 The association between late-life cognitive test scores and retrospective informant interview data Riccardo E. Marioni, Fiona E. Matthews and Carol Brayne (U.K.); MRC Cognitive Function and Ageing Study

280 A practical approach to assess depression risk and to guide risk reduction strategies in later life Osvaldo P. Almeida, Helman Alfonso, Jane Pirkis (Australia), Ngaire Kerse (New Zealand), Moira Sim, Leon Flicker, John Snowdon, Brian Draper, Gerard Byrne, Robert Goldney, Nicola T. Lautenschlager, Nigel Stocks (Australia), Marcia Scazufca (Brazil), Martijn Huisman (The Netherlands), Ricardo Araya (U.K.) and Jon Pfaff (Australia)

292 Habitual physical activity and the risk for depressive and anxiety disorders among older men and women Julie A. Pasco, Lana J. Williams, Felice N. Jacka, Margaret J. Henry, Carolyn E. Coulson, Sharon L. Brennan, Eva Leslie, Geoffrey C. Nicholson, Mark A. Kotowicz and Michael Berk (Australia)

299 The association between personality disorder and an act of deliberate self harm in the older person C. W. Ritchie, M. B. King, F. Nolan, S. O'Connor, M. Evans, N. Toms, G. Kitchen, S. Evans, C. Bielawski, D. Lee and M. Blanchard (U.K.)

308 A study of severe domestic squalor: 173 cases referred to an old age psychiatry service John Snowdon and Graeme Halliday (Australia)

315 Attitudes, knowledge, and interest: preparing university students to work in an aging world Daniela C. Gonçalves (Australia/Portugal), Joana Guedes, António M. Fonseca, Fernando Cabral Pinto, Inácio Martín (Portugal), Gerard J. Byrne and Nancy A. Pachana (Australia)

Case Reports 322 "In the midnight hour": a case report of musical hallucinations with multiple etiological factors treated with lamotrigine J. D. Huntley, A. Sandall and M. Philpot (U.K.)

325 Bupropion in the treatment of depression in Parkinson's disease Maria Załuska and Agnieszka Dyduch (Poland)

Letters

328

Book Reviews 335 